\title{
BEHAVIOR OF PLASTIC GREENHOUSES UNDER SYMMETRIC LOADING BEFORE AND AFTER STRENGTHENING WITH TENSION TIES
}

\author{
S.H. Lee ${ }^{1}$, K.J. Shin ${ }^{2, *}$ and H.D. Lee ${ }^{3}$ \\ ${ }^{I}$ Assistant Professor, School of Convergence \& Fusion System Engineering, \\ Kyungpook National University, 2559, Gyeongsang-daero, Sangju-si, Gyeongsangbuk-do, 37224, Republic of Korea \\ ${ }^{2}$ Professor, School of Architectural Engineering, \\ ${ }^{3}$ Associate Research Engineer, School of Architectural Engineering, \\ Kyungpook National University, 80 Daehak-ro, Buk-gu, Daegu 41566, Republic of Korea \\ *(Corresponding author: E-mail: shin@knu.ac.kr)
}

Received: 1 October 2017; Revised: 21 November 2017; Accepted: 13 December 2017

\begin{abstract}
In recent years, climate anomalies have led to major snowfall and heat waves causing immeasurable loss of life and property. Particularly, sudden snowfall led to the collapse of several plastic greenhouse in South Korea within the last five years. This study proposes a strengthening method that uses tension ties to prevent the collapse of plastic greenhouses. Five full-scale frames were prepared to investigate the strengthening effect of the ties. A frame included a controlled specimen without tension ties, and the other frames were strengthened frames. The variables in this study were divided into two categories: (a) tension tie materials consisting of a fiber rope and a steel wire and (b) pretension forces of $100 \mathrm{~N}$ and $200 \mathrm{~N}$. The testing results revealed that the normal frame failed in flexure, and that the failure of the strengthened frames occurred through out-of-plane buckling. The load capacities of the strengthened frames exceeded those of the reference frames without tension ties by $30 \%$ to $65 \%$.
\end{abstract}

Keywords: Plastic greenhouse, strengthening, tension tie, heavy snowfall, plastic hinge, flexure, collapse

DOI: $10.18057 /$ IJASC.2018.14.10

\section{INTRODUCTION}

Over the past five years, the number of plastic greenhouses that have collapsed in South Korea has increased (see Figure 1) because of sudden heavy snowfall and the insufficient resistance of greenhouse frames. In 2010, the total monetary amount of plastic greenhouse damage due to heavy snow reached approximately $\$ 19.9$ million, and the heavy snowfall of 2011 caused $\$ 20.4$ million in greenhouse damages according to an announcement by the National Disaster Information Center (NDIC) [1]. Additionally, in December 28, 2012, up to $100 \mathrm{~mm}$ of snow fell in the Pusan and Gyeongsangnam-do regions. This resulted in damages of $\$ 9.5$ million due to the partial and total damage of plastic greenhouses. Typically, Pusan and Gyeongsangnam-do areas were characterized by an absence of snowfall, and thus the snowfall in 2012 significantly damaged the plastic greenhouses in these areas. In December 2010, the Ministry for Food, Agriculture, Forestry and Fisheries (MIFAFF), and the Rural Development Administration (RDA) initiated a plan against these types of natural disasters [2]. The government actively encouraged the standardization of existing pipes for plastic greenhouses according to technical specifications of 2016. The limitations of steel pipe material included the following: 1) SPVHS or SPVHS-AZ with yield and tensile strength exceeding $295 \mathrm{MPa}$ and $400 \mathrm{MPa}$, respectively, should be always used for the structural pipes of plastic greenhouse; 2) The elongation of the pipe should exceed 20\%; and 3) A zinc galvanizing pipe with a thickness exceeding $6 \mu \mathrm{m}$ should be used to prevent corrosion at the weld zones. Furthermore, from 2017, the government will not pay compensation for damages to plastic greenhouses that do not use SPVHS or SPVHS-AZ. 
A greenhouse is shaped like an arch, but the actual behavior of a green house is closely associated with the frame. The greenhouse is created by bending a long single pipe into a curved arch element (or beam) and a vertical element (or column). The curved arch element and the vertical element are geometrically continuous without any connection element, as shown in Figure 2. The greenhouse is very weak, slender, and exhibits a limited ability to resist the forces because the bending moment is larger than the axial force due to external loads. In order to improve these weaknesses, several researches (Lee et al. [3]; Lee et al. [4]; Kim et al. [6]) proposed certain strengthening methods (such as horizontal bracing, X-type bracing, pillar supports, and high-performance sections) and carried out analyses to demonstrate the strengthening effect by using commercial software programs. In this study, a strengthening method using tension ties was temporarily set at the joint of the arch and the column when the snowfall was expected. The tie changed the frame behavior to tie-arch action in the greenhouse and increased the load capacity while tie installed. This study focused on the effect of the proposed strengthening method through experimental and analytical investigations of plastic greenhouses consisting of $\phi 25.4 \times 1.5 \mathrm{t} \mathrm{mm}$ SPVHS pipes. It may be noted that the SPVHS represented a zinc galvanized steel pipe used for vinyl housing structures in South Korea. The equivalent concentrated loading tests at four points were carried out in accordance with the roof slope factor for cold roofs based on ASCE/SEI 7-10 [7] or KBC 2009 [8]. Additionally, the results from a theoretical approach to flexural and plastic analyses, and a buckling analysis using a commercial software Midas Gen [9], were compared to the test results.

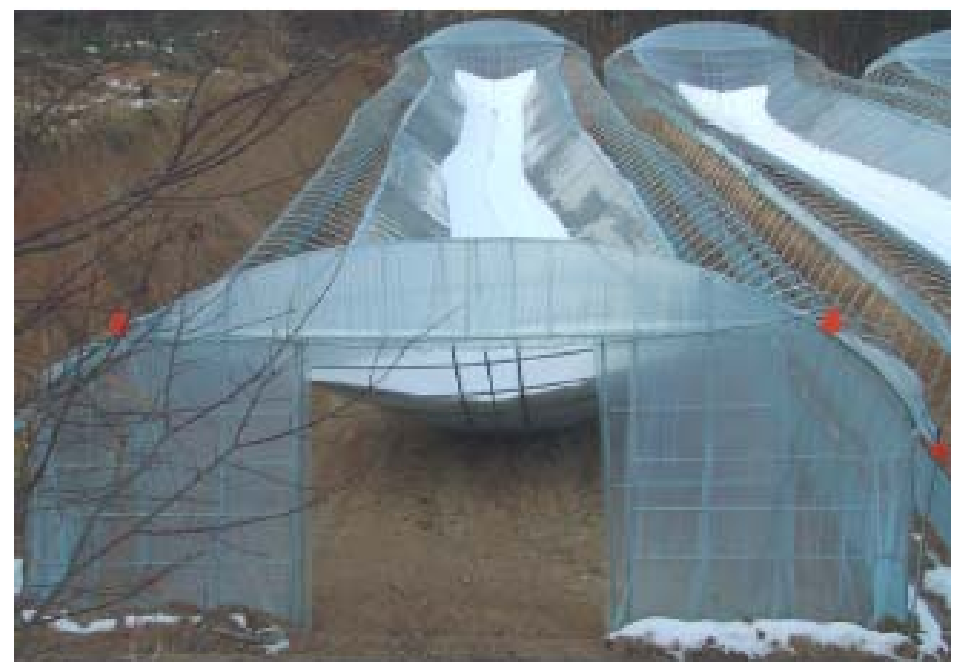

Figure 1. Collapse of a Plastic Greenhouse due to Heavy Snow

\section{EXPERIMETNAL PROGRAM}

\subsection{Test Specimens and Variables}

There are 18 kinds of plastic greenhouses with a single span against disasters in MIFAFF and RDA [2]. With respect to these greenhouses, the greenhouse frames with dimensions as illustrated in Figure 2 were designed for the loading test in this study. The distance $L_{1}$ between columns at the base was $6500 \mathrm{~mm}$; the distance $L_{2}$ between the tops of the columns was $6100 \mathrm{~mm}$; the vertical height $H_{1}$ was $1700 \mathrm{~mm}$ (it may be noted that the actual height of the column used in the analysis was approximately $1500 \mathrm{~mm}$, because the bottom of the column was inserted into a support); the arch rise $H_{2}$ was $1200 \mathrm{~mm}$; and the frame space s was $880 \mathrm{~mm}$. Seven crossbars were installed as braces between two frames, and four crossbars were set in loading positions. A pipe of $\phi 25.4 \times 1.5 \mathrm{t}$ $\mathrm{mm}$ was bent around a forming mold at room temperature. The arch part of the frame, particularly the top of the column, yielded in this bending process. The tension ties (such as a $\phi 4 \mathrm{~mm}$ steel wire 
or a fiber rope with dimensions of $37 \mathrm{~mm} \times 2 \mathrm{~mm}$ ) were connected at the tops of the columns, and pretension forces of $100 \mathrm{~N}$ or $200 \mathrm{~N}$ were determined to be within the ranges of human limits. Table 1 shows the test variables consisting of types of tension ties and pretension forces. The specimen names were defined according to the variables. Specifically, "FR" denoted frame; "6" represented a distance of $6500 \mathrm{~mm}$ between the bases; " 25 " symbolized $\phi 25.4 \times 1.5 \mathrm{t}$; "TR" and "TW" represented a tension rope tie and tension wire tie, respectively; and " 100 " and " 200 " corresponded to pretension forces.

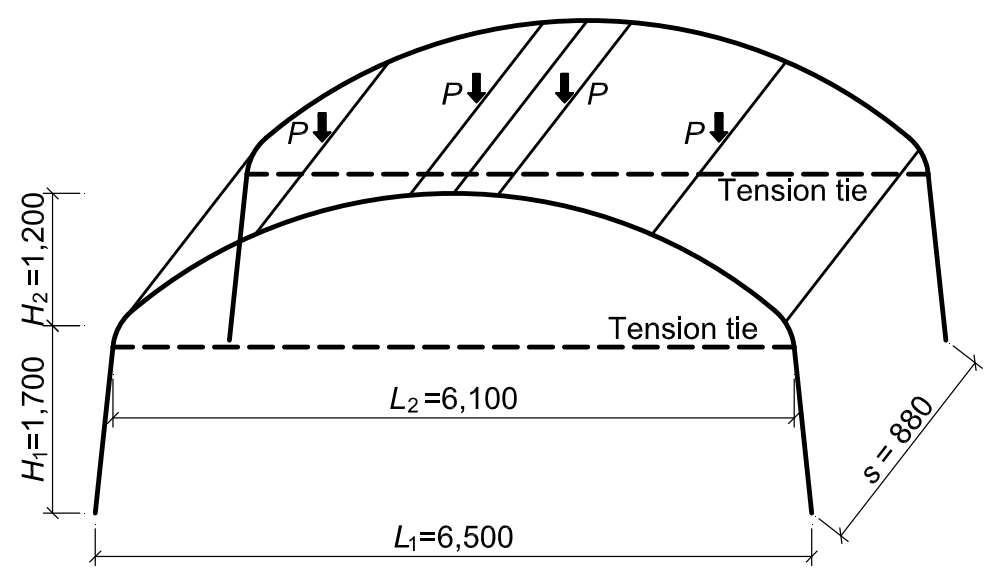

Figure 2. Dimensions of the Test Frame (unit: $\mathrm{mm}$ )

Table 1. Type and Pretension of Ties

\begin{tabular}{ccc}
\hline Specimen & Tie & Pretension (N) \\
\hline FR6-25 & - & - \\
FR6-25-TR-100 & Fiber rope* & 100 \\
FR6-25-TR-200 & Fiber rope & 200 \\
FR6-25-TW-100 & Steel wire* & 100 \\
FR6-25-TW-200 & Steel wire & 200 \\
\hline & \\
\hline & *Fiber rope \\
\hline & *Steel wire \\
\hline
\end{tabular}

\subsection{Material Properties}

The sectional and material properties of the pipe utilized in the study are summarized in Tables 2 and 3. The material properties of the pipe were obtained through stub-column testing, and the measured strengths exceeded the nominal strength. A length of the stub-column test specimen was three times the outer-diameter of pipe. The test was carried out on a universal test machine with a maximum capacity of $1000 \mathrm{kN}$. Based on the tensile tests for tension ties as shown in Table 1, the average ultimate load and stiffness corresponded to $5.49 \mathrm{kN}$ and $7.5 \mathrm{~N} / \mathrm{mm}$ for the fiber rope; and $10.15 \mathrm{kN}$ and $50 \mathrm{~N} / \mathrm{mm}$ for the steel wire, respectively. 
Table 2. Type and Pretension of Ties

\begin{tabular}{cccc}
\hline $\begin{array}{c}A \\
\left(\mathrm{~mm}^{2}\right)\end{array}$ & $\begin{array}{c}I \\
\left(\mathrm{~mm}^{4}\right)\end{array}$ & $\begin{array}{c}S \\
\left(\mathrm{~mm}^{3}\right)\end{array}$ & $\begin{array}{c}Z \\
\left(\mathrm{~mm}^{3}\right)\end{array}$ \\
\hline 112.6 & 8073.3 & 635.7 & 857.9 \\
\hline
\end{tabular}

Note: $A$ is the cross-sectional area; $I$ is the moment of inertia; $S$ is the section modulus; $Z$ is the plastic section modulus.

Table 3. Material Properties of a $\phi 25.4 \times 1.5 \mathrm{t}$ Pipe

\begin{tabular}{cccccc}
\hline \multirow{2}{*}{$\begin{array}{c}\text { Section } \\
(\mathrm{mm})\end{array}$} & \multicolumn{2}{c}{ Nominal strength } & \multicolumn{3}{c}{ Stub-column test } \\
& $F_{y}$ & $F_{u}$ & $F_{y}$ & $F_{u}$ & $F_{y} / F_{u}$ \\
$(\mathrm{MPa})$ & $(\mathrm{MPa})$ & $(\mathrm{MPa})$ & $(\mathrm{MPa})$ & $(\%)$ \\
\hline$\phi 25.4 \times 1.5 \mathrm{t}$ & $\geq 295$ & $\geq 400$ & 430 & 525 & 82 \\
\hline
\end{tabular}

Note: $F_{y}$ is the yield strength; $F_{u}$ is the ultimate strength.

\subsection{Sloped Roof Snow Loads based on ASCE/SEI 7-10}

Snow loads acting on a sloping surface were assumed to act on the horizontal projection of the surface. The sloped roof snow load $p_{s}$ could be obtained by multiplying the flat roof snow load $p_{f}$ by the roof slope factor $C_{s}$ as following Eq. 1 .

$p_{s}=C_{s} p_{f}$

where $C_{s}$ was assumed for cold roofs. Additionally, because the plastic (or vinyl) as covering materials for the greenhouse had unobstructed slippery surfaces that allowed the snow to slide off the eaves, $C_{s}$ was denoted by the dashed line as shown in Figure 7-2c of Chapter 7 in ASCE/SEI 7-10 [7] given by the following conditions: i) for slopes between $0^{\circ}$ and $15^{\circ}, C_{s}$ corresponded to 1.0 ; ii) for slopes above $70^{\circ}, C_{s}$ was considered free of snow loads; and iii) for slopes between $15^{\circ}$ and $70^{\circ}, C_{s}$ was calculated by linear interpolation. By assuming the plastic greenhouse was an unheated and open-air structure, the thermal factor $C_{t}$ was determined as 1.2. Given that the snow load $p_{s}$ was proportional to $C_{s}$, the equivalent four loading points according to $C_{s}$ are depicted in Figure 3. In the figure, $L_{a}$ is $1450 \mathrm{~mm}$; $L_{b}$ is $1400 \mathrm{~mm}$; and $L_{c}$ is $800 \mathrm{~mm}$.

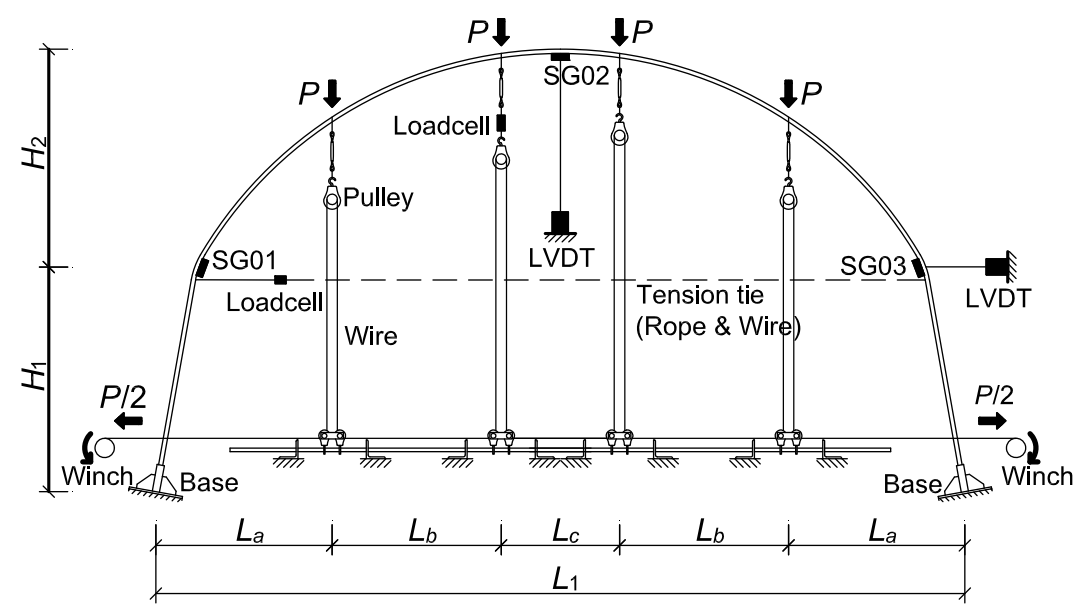

Figure 3. Positions of the Loading Points 


\subsection{Loading Method for Large Deformation}

It was difficult to load the structure using a general actuator or a universal testing machine in the case where an arch rise was high and the loading points were few, as shown in Figure 3. The arched jigs used to load the structure at a few points did not apply the load to the frame uniformly and did not continue loading when the arch frame collapsed and formed a large deformed shape. Hence, for the arch type frame, a loading apparatus that could uniformly act on the frame regardless of its indented shape and appropriately load the structure at a few points according to the number of pulleys was developed, as shown in Figure 3 [10].

Figure 4 shows the detailed view of the pulleys. Two pulleys at the bottom were merged into a fixed pulley to avoid splitting, and the fixed pulley could be easily moved from side-to-side by utilizing shackles to transfer vertical loads even when large lateral deformation occurred. Two winches as shown in Figure 5 were placed outside both ends of the frame and the loading was initiated by manually winding up these winches using a steel wire and a few pulleys, as illustrated in Figure 4.

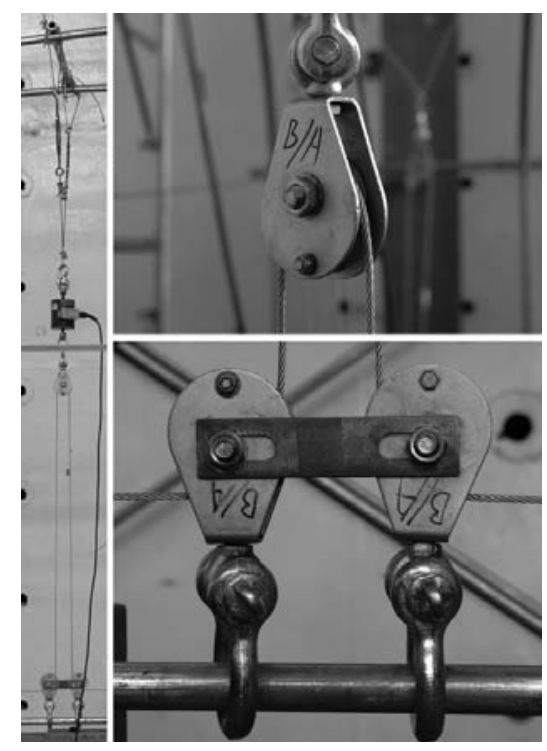

Figure 4. The Experimental Set-up Depicting a Movable Pulley at the Top and a Fixed Pulley at the Bottom

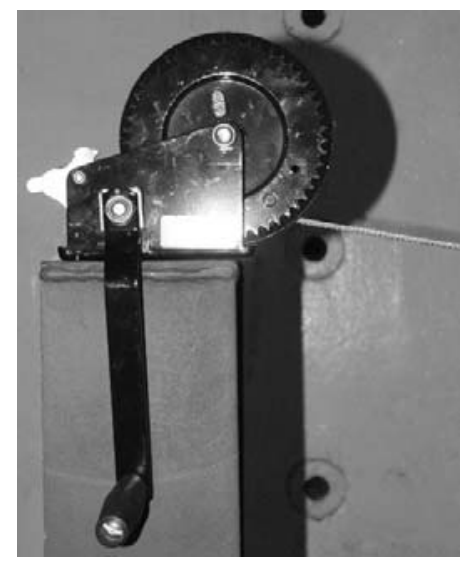

Figure 5. Winch used for Loading 
Figure 6 shows the devices used in the study for pretensioning the tension ties. A ratchet, shown in Figure $6 \mathrm{a}$, is a mechanical device that allows continuous linear or rotary motion in only one direction while preventing motion in the opposite direction. A turnbuckle in Figure $6 \mathrm{~b}$ is a device used for adjusting the tension or length of the wire. The pretension force and added tension by external loading were monitored through a load cell inserted between the tension ties (ropes or wires).

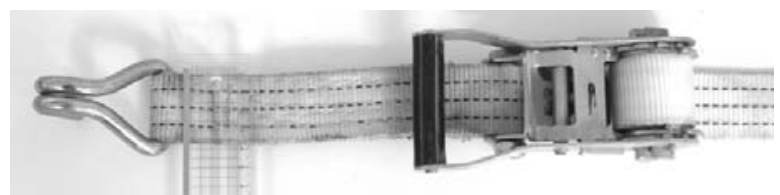

(a)

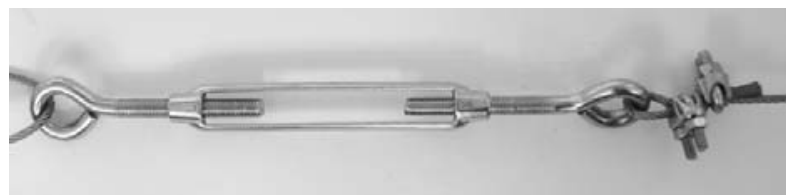

(b)

Figure 6. Device for Pretension: (a) Ratchet for the fiber rope; (b) Turn-buckle for the steel wire.

The greenhouse bases in the field were generally driven into the ground. In order to simulate this field condition, a fixed support consisting of a base plate with a cylinder, which was more rigid than the main pipe and enhanced with stiffeners, as shown in Figure 7, was used. The rigid cylinder was $200 \mathrm{~mm}$ deep.

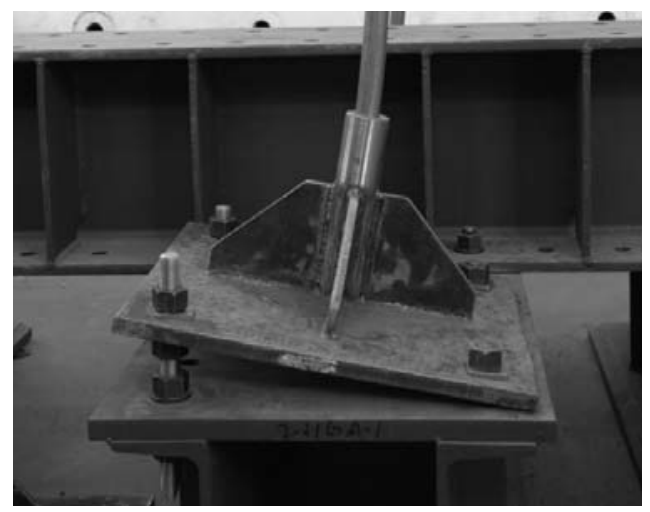

Figure 7. Fixed Support of Foundation

\section{$2.5 \quad$ Test Results}

Figure 8 illustrates the vertical load versus deflection at mid-span for all the specimens. The vertical load was half the value measured by the load cell because it corresponded to two frames. An unstrengthened frame failed in flexure at a deflection of $329 \mathrm{~mm}$, corresponding to a peak load of $228 \mathrm{~N}$. The uplift caused by the pretension was as follows: $12.2 \mathrm{~mm}$ for TR-100; $17.0 \mathrm{~mm}$ for TR-200; $10.8 \mathrm{~mm}$ for TW-100; and $23.3 \mathrm{~mm}$ for TW-200. The results of the FR6-25-TR-200 specimen indicated an error because the steel wire for the main vertical loading had been fixed when the pretension was applied. The main vertical loading after pretension was initiated at the uplift point. In the case of the strengthened frames with the fiber ropes, the load capacity increased by $35 \%$ and $41 \%$ but the deflection decreased by $59 \%$ and $54 \%$. The testing results revealed that the stiffness of the steel wire was 6.7 times that of the fiber rope, and thus the peak load substantially increased (by 58\% and 65\%) while indicating a $90 \%$ reduction in the deflection. All the strengthened frames failed in out-of-plane buckling. Additionally, the strains monitored by attached three strain gauges declined with the reduction of vertical and horizontal displacements. The test results are summarized in Table 4. 


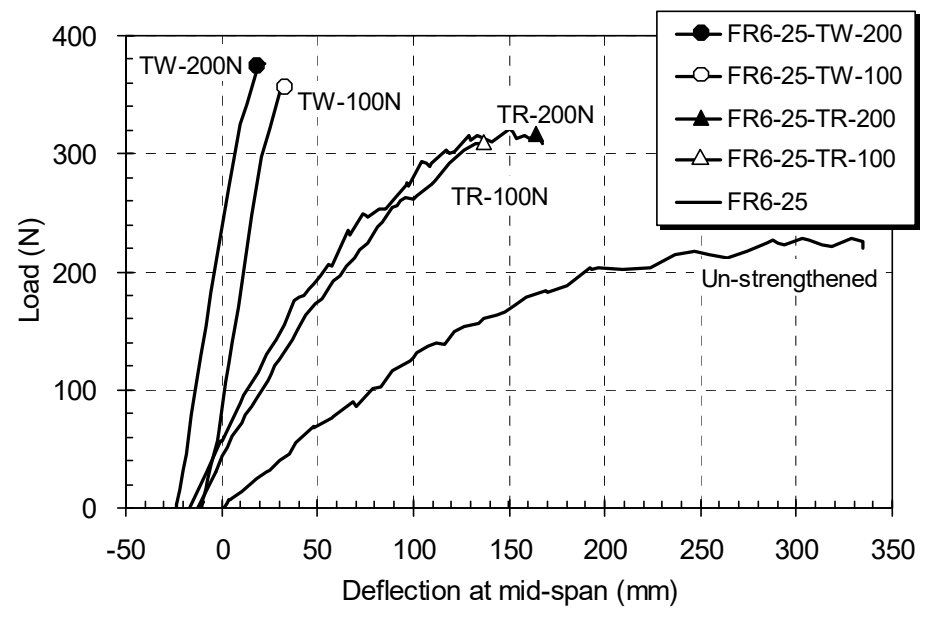

Figure 8. Load versus Deflection at Mid-span of all the Specimens

Table 4. Summary of the Test Results

\begin{tabular}{ccccccc}
\hline Specimen & $\begin{array}{c}\text { Uplift } \\
(\mathrm{mm})\end{array}$ & $\begin{array}{c}\text { Peak load (N) } \\
\text { Increase }\end{array}$ & $\begin{array}{c}\text { Deflection }(\mathrm{mm}) \\
\text { Decrease }\end{array}$ & $\begin{array}{c}\text { SG01 }(\mu \varepsilon) \\
\text { Decrease }\end{array}$ & $\begin{array}{c}\text { SG02 }(\mu \varepsilon) \\
\text { Decrease }\end{array}$ & $\begin{array}{c}\text { SG03 }(\mu \varepsilon) \\
\text { Decrease }\end{array}$ \\
\hline FR6-25 & - & 228 & 329 & -3038 & 4191 & -3317 \\
FR6-25-TR-100 & -12.2 & 309 & 136 & -1413 & 2298 & -1250 \\
& & $(35 \%)$ & $(-59 \%)$ & $(-53 \%)$ & $(-45 \%)$ & $(-62 \%)$ \\
FR6-25-TR-200 & -17.0 & 321 & 150 & -1383 & 2396 & -1252 \\
& & $(41 \%)$ & $(-54 \%)$ & $(-54 \%)$ & $(-43 \%)$ & $(-62 \%)$ \\
FR6-25-TW-100 & -10.8 & 361 & 32 & -143 & 441 & 409 \\
& & $(58 \%)$ & $(-90 \%)$ & $(-95 \%)$ & $(-89 \%)$ & $(-112 \%)$ \\
FR6-25-TW-200 & -23.3 & 377 & 23 & -71 & 399 & 658 \\
& & $(65 \%)$ & $(-93 \%)$ & $(-98 \%)$ & $(-90 \%)$ & $(-120 \%)$ \\
\hline
\end{tabular}

The failure of the unstrengthened frame occurred through in-plane flexural failure mode. The plastic hinges formed at the tops of the columns and both supports. Conversely, the strengthened frames failed in out-of-plane buckling (see Figure 9).
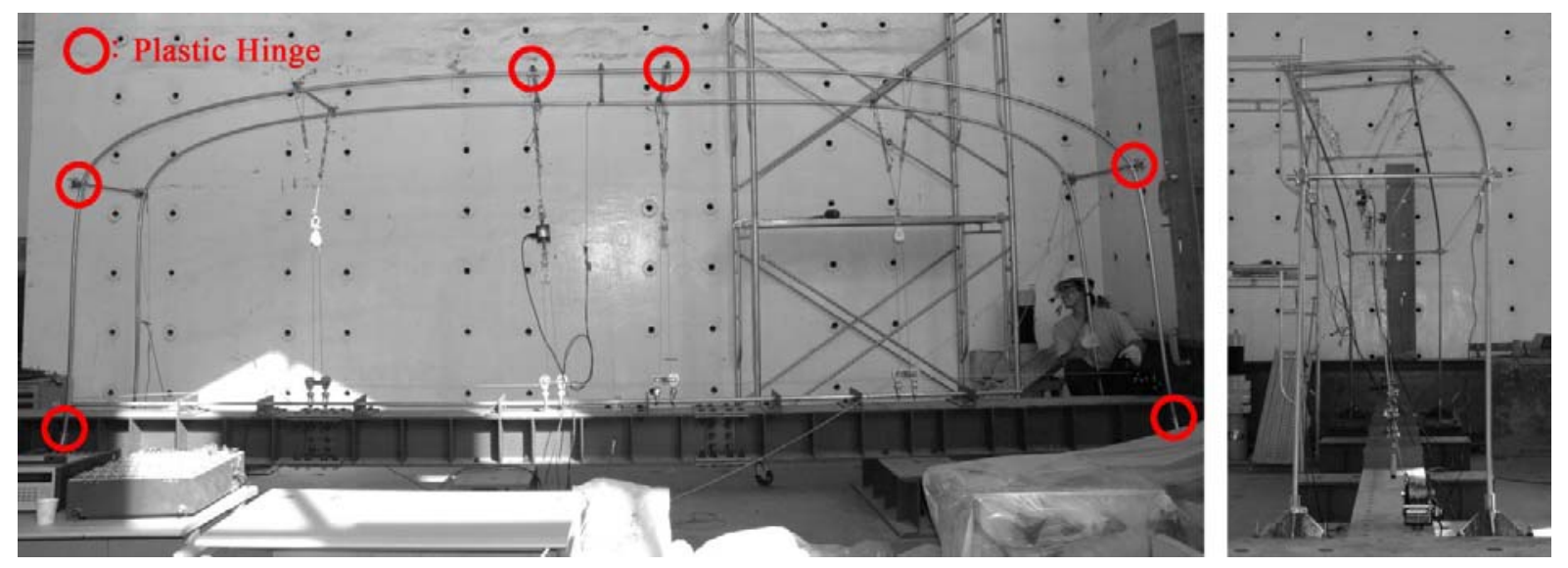

Figure 9. Failure Mode (left: unstrengthened frame; right: strengthened frame with tension ties) 
In next section, a flexural analysis and a plastic analysis were conducted to evaluate the elastic behavior and the collapse load, respectively for an unstrengthened frame. A buckling analysis using a commercial program was also performed for the strengthened frame.

\section{ANALYSIS METHOD}

The applied load-vertical deflection relationship for greenhouses with or without tension ties was determined by using a bilinear relationship through analytical approaches (e.g. flexural, plastic, and buckling analysis). The first stage involved a linear elastic state using flexural analysis. The second stage included the establishment of the peak load by a plastic analysis using the failure mechanism for the unstrengthened frame or the buckling load results obtained by Midas Gen software for the strengthened frame.

\subsection{Flexural Analysis}

The plastic greenhouse was arranged in a symmetric form. Responses including member forces and deformations of the entire structure under any loading could be obtained from the responses of one of the portions of the structure separated by the axis of symmetry [11]. The plastic greenhouse could be considered as symmetric with respect to an $\mathrm{OE}$ axis as illustrated in Figure 10. Point A was considered as fixed by the foundation shown in Figure 7, and point $\mathrm{E}$ on the symmetric axis was assumed to have horizontal displacement and moment that were fixed. A horizontal spring with a stiffness of $k_{B}$ at point B was used to model the tension tie (but $k_{B}$ was zero in the unstrengthened frame), and an imaginary vertical spring at point $E$ was used to calculate the vertical deflection (it may be noted that $k_{E}$ was zero in all the frames). Hence, the unstrengthened frame had two redundants $\left(M_{E}\right.$ and $\left.H_{E}\right)$, and the strengthened frame had three redundants $\left(H_{E}, M_{E}\right.$, and $\left.F_{B}\right)$.

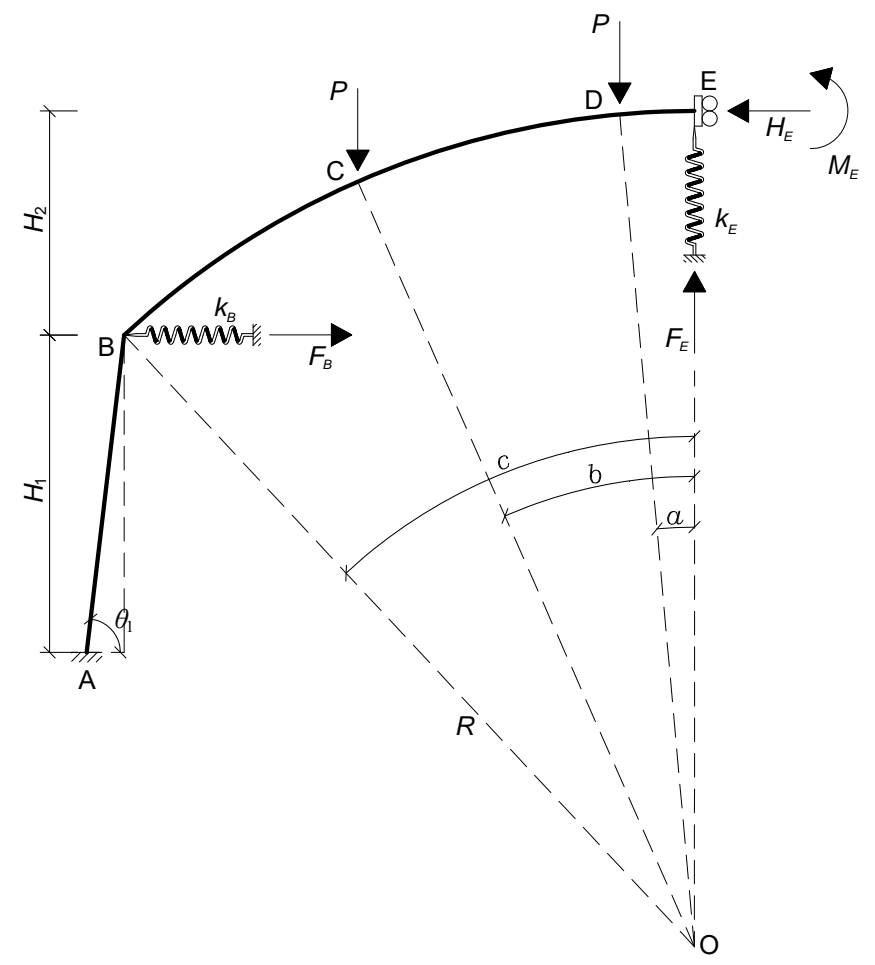

Figure 10. Analysis Model for Flexural Analysis (note that $\mathrm{a}, \mathrm{b}$ and $\mathrm{c}$ are in radians) 
The unknown values of $H_{E}, M_{E}, \delta_{E, v}$, and $\delta_{B, h}$ that denoted a horizontal reaction force, a moment reaction, a vertical deflection at point $\mathrm{E}$, and a horizontal displacement at point $\mathrm{B}$, respectively, were calculated through a linearly elastic analysis using Castigliano's theorem. First, the bending moment distributions are determined as follows:

(i) for the region corresponding to $0 \leq \theta \leq a$ ( $\theta$ is varied from point $\mathrm{E}$ to $\mathrm{B}$ )

$M_{\theta}=M_{E}+H_{E} R[1-\cos \theta]+F_{E} R \sin \theta$

(ii) for the region corresponding to $a \leq \theta \leq b$ ( $\theta$ is varied from point $\mathrm{D}$ to $\mathrm{C}$ )

$$
\begin{aligned}
M_{\theta}= & M_{E}+H_{E} R[1-\cos (\theta+a)] \\
& +F_{E} R \sin (\theta+a)-P R[\sin (\theta+a)-\sin a]
\end{aligned}
$$

(iii) for the region corresponding to $a \leq \theta \leq c$ ( $\theta$ is varied from point $\mathrm{C}$ to $\mathrm{B})$

$$
\begin{aligned}
M_{\theta}= & M_{E}+H_{E} R[1-\cos (\theta+b)]+F_{E} R \sin (\theta+b) \\
& -P R[2 \sin (\theta+b)-(\sin a+\sin b)]
\end{aligned}
$$

(iv) for the region corresponding to $0 \leq s \leq H_{1}$ ( $s$ is varied from point $\mathrm{B}$ to A)

$$
\begin{aligned}
M_{s}= & M_{E}+H_{E}[R(1-\cos c)+s]+F_{E}\left[R \sin c+s \tan \left(\pi / 2-\theta_{1}\right)\right] \\
& -P\left[R(2 \sin c-\sin a-\sin b)+2 s \tan \left(\pi / 2-\theta_{1}\right)\right]-F_{B} s
\end{aligned}
$$

where $M_{\theta}$ is the bending moment at arbitrary $\theta ; M_{E}$ and $H_{E}$ are the moment reaction and the horizontal reaction force at point $\mathrm{E}$, respectively; $R$ is the radius of the $\operatorname{arch} ; F_{E}$ is the imaginary force due to a vertical spring at point $\mathrm{E} ; F_{B}$ is the force applied to the spring (e.g., tension tie) at point $\mathrm{B} ; P$ is the external load; $a$ is the angle between point $\mathrm{E}$ and $\mathrm{D} ; b$ is the angle between point $\mathrm{E}$ and $\mathrm{C}$; $c$ is the angle between point $\mathrm{E}$ and $\mathrm{B} ; \theta_{1}$ is the angle of the column with respect to the ground; and $s$ is the arbitrary vertical distance from point $\mathrm{B}$ to $\mathrm{A}$.

Second, the deformations of the main points were determined by Castigliano's theorem. The rotation $\theta_{E}$, the horizontal displacement $\delta_{E, h}$ and the vertical deflection $\delta_{E, v}$ of point $\mathrm{E}$ are given as following Eqs. 3-5.

$$
\begin{aligned}
\theta_{E} & =\frac{1}{E I}\left(\int_{0}^{s} \frac{M_{\theta} \partial M_{\theta}}{\partial M_{E}} d s+\int_{0}^{H_{1}} \frac{M_{s} \partial M_{s}}{\partial M_{E}} d s\right) \\
= & \frac{1}{E I}\left(\int_{0}^{c} \frac{M_{\theta} \partial M_{\theta}}{\partial M_{E}} R d \theta+\int_{0}^{H_{1}} \frac{M_{s} \partial M_{s}}{\partial M_{E}} d s\right) \\
\delta_{E, h} & =\frac{1}{E I}\left(\int_{0}^{s} \frac{M_{\theta} \partial M_{\theta}}{\partial H_{E}} d s+\int_{0}^{H_{1}} \frac{M_{s} \partial M_{s}}{\partial H_{E}} d s\right) \\
& =\frac{1}{E I}\left(\int_{0}^{c} \frac{M_{\theta} \partial M_{\theta}}{\partial H_{E}} R d \theta+\int_{0}^{H_{1}} \frac{M_{s} \partial M_{s}}{\partial H_{E}} d s\right)
\end{aligned}
$$




$$
\begin{aligned}
\delta_{E, v} & =\frac{1}{E I}\left(\int_{0}^{s} \frac{M_{\theta} \partial M_{\theta}}{\partial F_{E}} d s+\int_{0}^{H_{1}} \frac{M_{s} \partial M_{s}}{\partial F_{E}} d s\right) \\
& =\frac{1}{E I}\left(\int_{0}^{c} \frac{M_{\theta} \partial M_{\theta}}{\partial F_{E}} R d \theta+\int_{0}^{H_{1}} \frac{M_{s} \partial M_{s}}{\partial F_{E}} d s\right)
\end{aligned}
$$

where $E$ is the modulus of elasticity of the pipe; $I$ is the moment of inertia of the pipe, and $\theta_{E}$ and $\delta E, h$ are zero because rotation and horizontal displacement are fixed at point $\mathrm{E}$.

The $F_{B}$ term was considered only in the column because there was no $F_{B}$ term in the arch region $(0$ $\leq \theta \leq c)$. As a result, the horizontal displacement $\delta_{B, h}$ at point $\mathrm{B}$ could be calculated by the following Eq. 6.

$$
\delta_{B, h}=\frac{1}{E I} \int_{0}^{H_{1}} \frac{M_{s} \partial M_{s}}{\partial F_{B}} d s
$$

Substituting Eq. 2 into Eqs. 3-6, the equations for the unknown values could be expressed in matrix form as shown below:

$$
\frac{1}{E I}\left[\begin{array}{llll}
k_{11} & k_{12} & k_{13} & k_{14} \\
k_{21} & k_{22} & k_{23} & k_{24} \\
k_{31} & k_{32} & k_{33} & k_{34} \\
k_{41} & k_{42} & k_{43} & k_{44}
\end{array}\right]\left[\begin{array}{c}
M_{E} \\
H_{E} \\
F_{E} \\
F_{B}
\end{array}\right]-\frac{P}{E I}\left[\begin{array}{c}
p_{1} \\
p_{2} \\
p_{3} \\
p_{4}
\end{array}\right]=\left[\begin{array}{c}
0 \\
0 \\
\delta_{E, v} \\
\delta_{B, h}
\end{array}\right]
$$

The spring forces $F_{B}$ and $F_{E}$ could be defined by using Hooke's law (i.e., $F_{B}=-k_{B} \delta_{B, h}$ and $F_{E}=$ $\left.-k_{E} \delta_{E, v}\right)$. The negative sign indicates that the spring reaction force and the deformation force are in opposite directions. After replacing $F_{E}$ and $F_{B}$ and rearranging, the matrix form could be rewritten as shown Eqs 8a or 8b.

$$
\begin{aligned}
& {\left[\begin{array}{cccc}
k_{11} & k_{12} & k_{13}\left(-k_{E}\right) & k_{14}\left(-k_{B}\right) \\
k_{21} & k_{22} & k_{23}\left(-k_{E}\right) & k_{24}\left(-k_{B}\right) \\
k_{31} & k_{32} & k_{33}\left(-k_{E}\right)-E I & k_{34}\left(-k_{B}\right) \\
k_{41} & k_{42} & k_{43}\left(-k_{E}\right) & k_{44}\left(-k_{B}\right)-E I
\end{array}\right]\left[\begin{array}{c}
M_{E} \\
H_{E} \\
\delta_{E, v} \\
\delta_{B, h}
\end{array}\right]=P\left[\begin{array}{c}
p_{1} \\
p_{2} \\
p_{3} \\
p_{4}
\end{array}\right]} \\
& {[\bar{K}][\bar{U}]=[\bar{P}]}
\end{aligned}
$$

where the components $\left(k_{i i}\right.$ and $\left.p_{i}\right)$ of the matrix are summarized in the Appendix. In order to obtain the unknown matrix $[\bar{U}]$ of the unstrengthened frame, " $k_{B}=0$ " was inserted into the matrix. In the frames with the tension ties, values of twice the stiffness measured by the tensile test were applied since the analysis model shown in Figure 10 corresponded to half of the entire structure. Hence, $k_{B}$ was $15 \mathrm{~N} / \mathrm{mm}$ for the fiber rope and $100 \mathrm{~N} / \mathrm{mm}$ for the steel wire. The externally applied load $P$ (that was a collapse load) for the greenhouse frame was obtained through a plastic or buckling analysis as described in the next section.

The initial deformations and redundants resulting from pretensioning could be obtained by changing the right side of Eq. 8 and substituting $k_{B}=k_{E}=0$. The right side components could be replaced with equations representing the pretensioning force $P_{\text {pre }}$ as following Eq. 9. 


$$
P_{p r e}\left[\begin{array}{c}
\frac{1}{2} H_{1}{ }^{2} \\
\frac{1}{2} R H_{1}{ }^{2}(1-\cos c)+\frac{1}{3} H_{1}^{3} \\
\frac{1}{2} R H_{1}{ }^{2} \sin c+\frac{1}{3} H_{1}^{3} \tan \left(\pi / 2-\theta_{1}\right) \\
-\frac{1}{3} H_{1}^{3}
\end{array}\right]
$$

Figure 11 shows the three relative bending moment distributions resulting from the external load when there was no pretension tie or when there was rope or wire as a tie irrespective of the pretension force. The bending moment in a frame without a tie was much larger than that in a frame with a rope or wire. The decreased bending moment distribution demonstrated the effect of using a pretension tie. A frame without a tie had large bending moments at points A, B, D and E. In an unstrengthened frame, the bending moment was approximately zero at loading point $\mathrm{C}$ on the arch and was $700 \mathrm{~mm}$ away from the top of the column. When the rope or wire was used as a strengthening material, the moment distribution between points $\mathrm{B}$ and $\mathrm{C}$ was visibly changed. In other words, a bending moment at point B (top of column) in an unstrengthened frame was large, but following the strengthening, the moments were larger at points between points $\mathrm{B}$ and $\mathrm{C}$ or loading point $\mathrm{D}$.

Assuming that the stiffness of the tie was infinite, the result was not significantly different from that of a frame with wire tie $\left(k_{B}=100 \mathrm{~N} / \mathrm{mm}\right)$. However, the moment sign in the lower part of the column was reversed when compared with $k_{B}=100 \mathrm{~N} / \mathrm{mm}$. If ties with stiffnesses of $5,15,100$, and $\infty \mathrm{N} / \mathrm{mm}$ were used as strengthening materials, the maximum moments decreased by $63 \%, 35 \%$, $22 \%$, and $18 \%$, respectively. Thus, any fiber material at hand could help prevent flexural failure in plastic greenhouses caused by heavy snowfall.

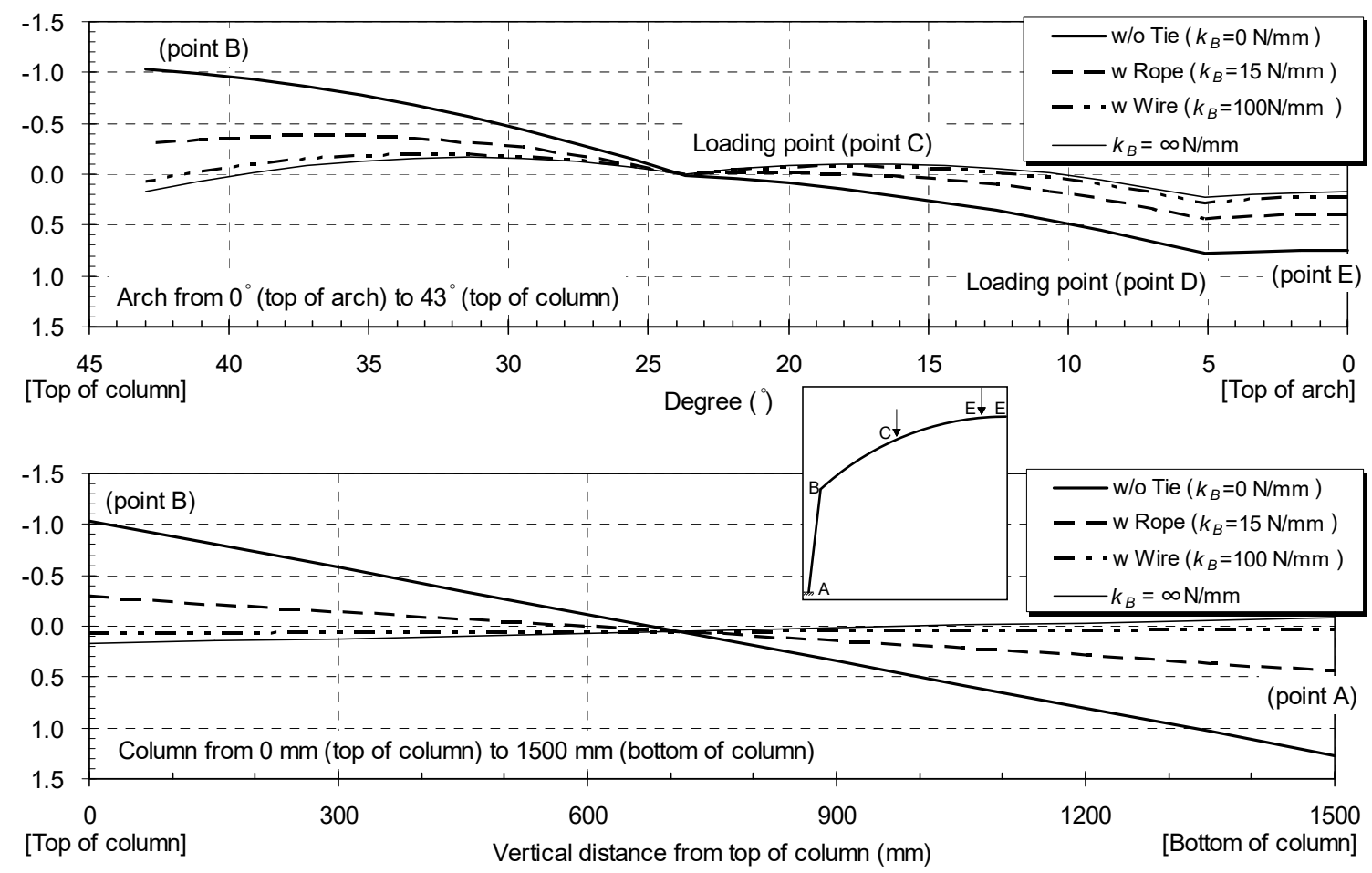

Figure 11. Bending Moment Diagram by the External Load 


\subsection{Plastic Analysis of Unstrengthened Model}

The plastic analysis using a virtual work method reported by Lee et al. [12] is introduced in this section. The unstrengthened frame failed in flexure while forming plastic hinges at three points, namely at the top of the column, the support, and the loading point $\mathrm{D}$ corresponding to points $\mathrm{A}, \mathrm{B}$, and $\mathrm{D}$, respectively. The collapse mode is shown in Figure 9. If the plastic moment capacity of the straight pipe prior to bending was assumed as $M_{p}$, a moment capacity at the base (point A) indicated a positive $M_{p}$ when subjected to an external load $P$. The plastic moment capacities at points $\mathrm{B}, \mathrm{C}, \mathrm{D}$, and $\mathrm{E}$ could be assumed as $\beta M_{p}, \gamma M_{p}, \eta M_{p}$, and $\lambda M_{p}$, respectively, because these sections were deformed due to plastic bending (see Figure 12a). However, the magnitudes of $\gamma, \eta$, and $\lambda$ factors were defined as " 1 " since the deformation was small and that of $\beta$ was assumed as 0.8 because of the excessive deformation. A dashed line indicated an undeflected shape before loading, and a solid line denoted a deflected shape after loading. Points denoted by ' $\bullet$ ' show the assumed plastic hinge locations. Figure $12 \mathrm{~b}$ is an analytical model presented for simplicity.

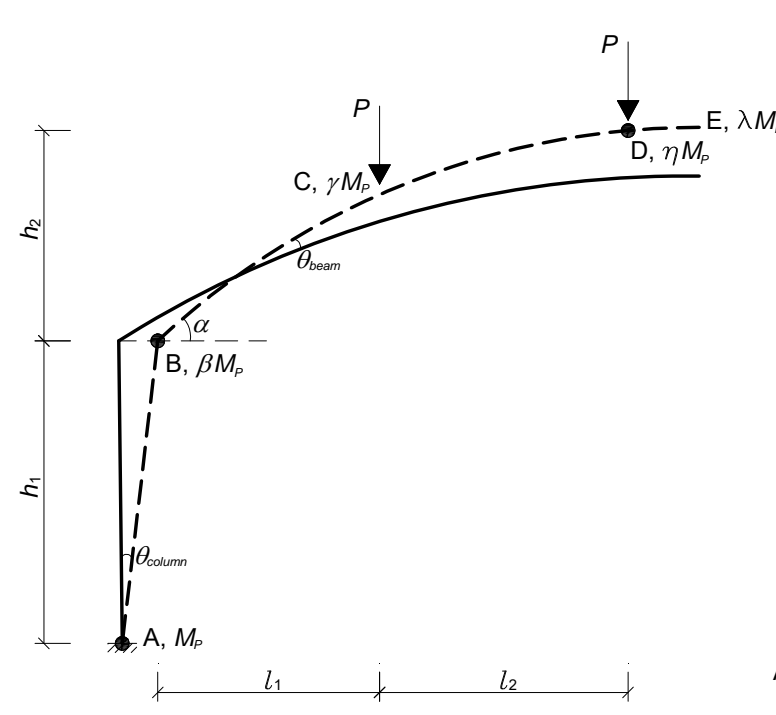

(a)

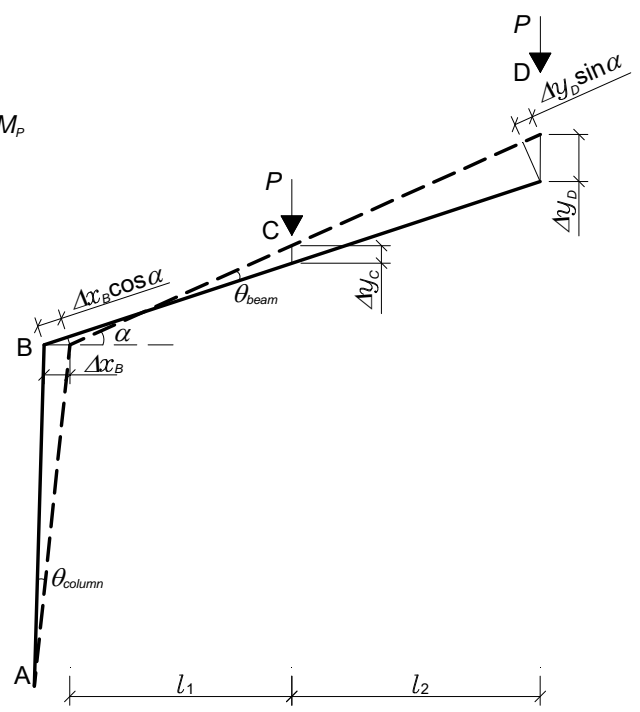

(b)

Figure 12. Determinate Arch Frame subjected to Applied Loads and Plastic Hinges:

(a) Deformed shape of plastic greenhouse; (b) Deformed shape for simplicity.

In Figure $12 \mathrm{~b}$, a horizontal displacement at point $\mathrm{B}\left(\Delta x_{B}\right)$ and a vertical deflection at point $\mathrm{D}\left(\Delta y_{D}\right)$ could be expressed by the following Eqs. 10 and 11.

$\Delta x_{B}=h_{1} \theta_{\text {column }}$

$\Delta y_{D}=\sqrt{\left(l_{1}+l_{2}\right)^{2}+h_{2}^{2}} \theta_{\text {beam }} \cos \alpha$

Assuming that beam length was not changed before and after the external loading, $\Delta x_{B}$ and $\Delta y_{D}$ shared the following relationship of Eq. 12 .

$\Delta y_{D} \sin \alpha=\Delta x_{B} \cos \alpha$

From Eqs. 10-12, $\theta_{\text {column }}$ and $\theta_{\text {beam }}$ could be rearranged as the following Eq. 13. 
$\theta_{\text {column }}=\frac{\sqrt{\left(l_{1}+l_{2}\right)^{2}+h_{2}^{2}} \sin \alpha}{h_{1}} \theta_{\text {beam }}$

The internal work $\left(W_{i}\right)$ at the plastic hinges and the external work $\left(W_{e}\right)$ by the external loading were calculated by using the following Eqs. 14 and 15.

$$
\begin{aligned}
W_{i} & =M_{p} \theta_{\text {column }}+\beta M_{p}\left(\theta_{\text {column }}+\theta_{\text {beam }}\right)+M_{p} \theta_{\text {beam }} \\
& =(1+\beta) M_{p}\left(\theta_{\text {column }}+\theta_{\text {beam }}\right) \\
& =(1+\beta) M_{p}\left[\frac{\sqrt{\left(l_{1}+l_{2}\right)^{2}+h_{2}^{2}} \sin \alpha}{h_{1}}+1\right] \theta_{\text {beam }} \\
W_{e} & =\left(\Delta y_{C}+\Delta y_{D}\right) P \\
& =\left(\frac{2 l_{1}+l_{2}}{l_{1}+l_{2}}\right) \Delta y_{D} P \\
& =\left(\frac{2 l_{1}+l_{2}}{l_{1}+l_{2}}\right) \sqrt{\left(l_{1}+l_{2}\right)^{2}+h_{2}^{2}} \theta_{\text {beam }} \cos \alpha P
\end{aligned}
$$

Finally, the collapse load $P_{p}$ was expressed as following Eq. 16.

$$
P_{p}=(1+\beta) M_{p}\left[\frac{\sqrt{\left(l_{1}+l_{2}\right)^{2}+h_{2}^{2}} \sin \alpha}{h_{1}}+1\right] /\left(\frac{2 l_{1}+l_{2}}{l_{1}+l_{2}}\right) \sqrt{\left(l_{1}+l_{2}\right)^{2}+h_{2}^{2}} \cos \alpha
$$

where $h_{1}$ and $h_{2}$ denoted the height of column and the vertical height between points $\mathrm{B}$ and $\mathrm{D}$, respectively; $\theta_{\text {column }}$ is the plastic rotation at column bottom; $l_{1}$ is the horizontal distance between points $\mathrm{B}$ and $\mathrm{C} ; l_{2}$ is the horizontal distance between points $\mathrm{C}$ and $\mathrm{D} ; \theta_{\text {beam }}$ is the plastic rotation of the beam element; $\alpha$ is the angle between beam and column elements; and $\Delta y_{C}$ and $\Delta y_{D}$ are the vertical deflections at point $\mathrm{C}$ and $\mathrm{D}$, respectively. From the plastic analysis above, the collapse load in an unstrengthened frame was conservatively computed as approximately $304 \mathrm{~N}$.

\subsection{Buckling Analysis of Strengthened Model}

For the buckling analysis, the analytical model was generated with a commercial software, Midas Gen. In this section, a linear (eigenvalue) buckling analysis was performed to obtain the critical load factors and buckling mode shapes. The equilibrium equation shown in Eq. 17 was formulated as an eigenvalue equation where $K$ is the elastic stiffness of the greenhouse; $\lambda$ is the eigenvalue or buckling load factor; $K_{G}$ is the additional geometric stiffness due to the stresses caused by the initial loading; and $U$ is the displacement of the greenhouse as indicated by the following Eq. 17.

$$
\left[K+\lambda K_{G} \rrbracket[U]=0\right.
$$

The strengthened frame failed in out-of-plane buckling in the first buckling mode shape at buckling loads of $361 \mathrm{~N}$ and $427 \mathrm{~N}$ as shown in Figure 13. 


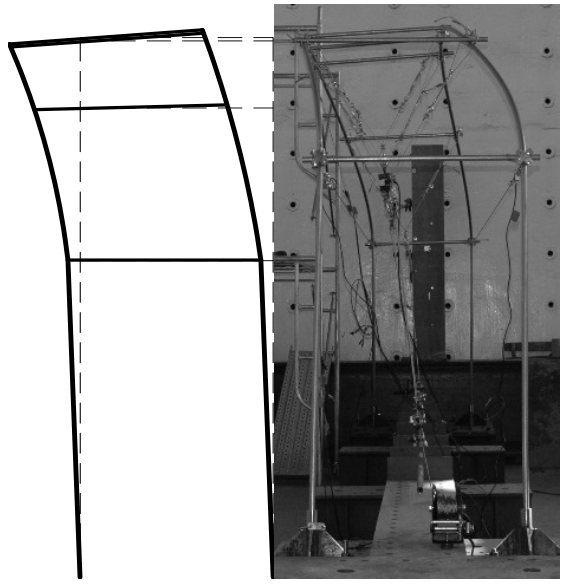

(a)

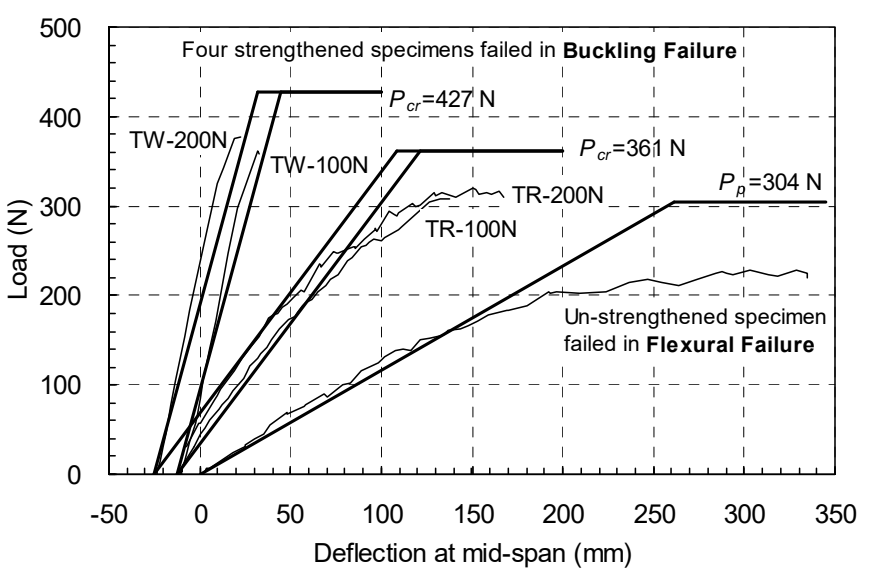

(b)

Figure 13. Results of the Test and Analyses:

(a) Buckling mode in the strengthened specimen; (b) Load-deflection curves of all the specimens

\section{SUMMARY AND CONCLUSION}

In this study, a strengthening method using tension ties (i.e., fiber rope and steel wire) was proposed to prevent plastic greenhouse collapse due to heavy snow in South Korea. The equivalent concentrated loading test at four points and analytical approaches were carried out. The test results indicated that the tension tie could increase the load capacity by $35 \%-65 \%$. The strengthened arch frames failed due to out-of-plane buckling during the test, which indicated a high probability of increasing the load capacity if out-of-plane buckling was prevented. Specifically, because the plastic greenhouse frame was restricted by the cover material (or vinyl) and rope (for preventing the flapping of the cover material) in the field, the collapse resulting from heavy snowfall was due to flexural failure rather than buckling (see Figure 1). Furthermore, in unstrengthened plastic greenhouse frames, the flexural elastic and plastic analyses could predict the responses including elastic stiffness and collapse load.

\section{ACKNOWLEDGEMENT}

This research was supported by Fire Fighting Safety \& 119 Rescue Technology Research and Development Program funded by the Ministry of Public Safety and Security (MPSS-fire safety-2015-72) and Basic Science Research Program through the National Research Foundation of Korea (NRF) funded by the Ministry of Science, ICT \& Future Planning (No. NRF-2015R1C1A1A01054899).

\section{APPENDIX}

$k_{11}=R c+H_{1}$

$k_{12}=R^{2}(c-\sin c)+R H_{1}(1-\cos c)+\frac{1}{2} H_{1}^{2}$ 


$$
\begin{aligned}
& k_{13}=R^{2}(1-\cos c)+R H_{1} \sin c+\frac{1}{2} H_{1}^{2} \tan \left(\pi / 2-\theta_{1}\right) \\
& k_{14}=-\frac{1}{2} H_{1}^{2} \\
& k_{21}=k_{12} \\
& k_{22}=R^{3}\left(\frac{3}{2} c-2 \sin c+\frac{\sin 2 c}{4}\right)+R^{2} H_{1}(1-\cos c)^{2}+R H_{1}^{2}(1-\cos c)+\frac{1}{3} H_{1}^{3} \\
& k_{23}=R^{3}\left(\frac{3}{4}-\cos c+\frac{\cos 2 c}{4}\right)+R^{2} H_{1}(1-\cos c) \sin c \\
& +\frac{1}{2} R H_{1}^{2}\left[(1-\cos c) \tan \left(\pi / 2-\theta_{1}\right)+\sin c\right]+\frac{1}{3} H_{1}^{3} \tan \left(\pi / 2-\theta_{1}\right) \\
& k_{24}=-\frac{1}{2} R H_{1}^{2}(1-\cos c)-\frac{1}{3} H_{1}^{3} \\
& k_{31}=k_{13} \\
& k_{32}=k_{23} \\
& k_{33}=R^{3}\left(\frac{c}{2}-\frac{\sin 2 c}{4}\right)+R^{2} H_{1} \sin ^{2} c+R H_{1}^{2} \sin c \tan \left(\pi / 2-\theta_{1}\right)+\frac{1}{3} H_{1}^{3} \tan ^{2}\left(\pi / 2-\theta_{1}\right) \\
& k_{34}=-\frac{1}{2} R H_{1}^{2} \sin c-\frac{1}{3} H_{1}^{3} \tan \left(\pi / 2-\theta_{1}\right) \\
& k_{41}=k_{14} \\
& k_{42}=k_{24} \\
& k_{43}=k_{34} \\
& k_{44}=\frac{1}{3} H_{1}^{3} \\
& p_{1}=R^{2}[(\cos a-\cos b)+(a-b) \sin a+2(\cos b-\cos c)+(b-c)(\sin a+\sin b)] \\
& +R H_{1}(2 \sin c-\sin a-\sin b)+H_{1}^{2} \tan \left(\pi / 2-\theta_{1}\right) \\
& p_{2}=R^{3}\left[\begin{array}{l}
(\cos a-\cos b)+(a-b) \sin a-\frac{\cos 2 a-\cos 2 b}{4}-\sin a(\sin a-\sin b)+2(\cos b-\cos c) \\
+(b-c)(\sin a+\sin b)-\frac{\cos 2 b-\cos 2 c}{2}-(\sin a+\sin b)(\sin b-\sin c)
\end{array}\right] \\
& +R^{2} H_{1}(1-\cos c)(2 \sin c-\sin a-\sin b) \\
& +R H_{1}^{2}\left[(1-\cos c) \tan \left(\pi / 2-\theta_{1}\right)+\frac{1}{2}(2 \sin c-\sin a-\sin b)\right] \\
& +\frac{2}{3} H_{1}^{3} \tan \left(\pi / 2-\theta_{1}\right)
\end{aligned}
$$




$$
\begin{aligned}
p_{3}= & R^{3}\left[\begin{array}{l}
\frac{1}{2}(b-a)+\frac{\sin 2 a-\sin 2 b}{4}-\sin a(\cos a-\cos b)+(c-b) \\
+\frac{\sin 2 b-\sin 2 c}{2}-(\sin a+\sin b)(\cos b-\cos c)
\end{array}\right] \\
& +R^{2} H_{1}(2 \sin c-\sin a-\sin b) \sin c \\
& +R H_{1}{ }^{2} \tan \left(\pi / 2-\theta_{1}\right)\left[\sin c+\frac{1}{2}(2 \sin c-\sin a-\sin b)\right] \\
& +\frac{2}{3} H_{1}{ }^{3} \tan ^{2}\left(\pi / 2-\theta_{1}\right) \\
p_{4}= & -\left[\frac{1}{2} R H_{1}{ }^{2}(2 \sin c-\sin a-\sin b)+\frac{2}{3} H_{1}{ }^{3} \tan ^{2}\left(\pi / 2-\theta_{1}\right)\right]
\end{aligned}
$$

\section{REFERENCES}

[1] National Disaster Information Center (NDIC), http://www.safekorea.go.kr (in Korea).

[2] Ministry for Food, Agriculture, Forestry and Fisheries (MIFAFF) and Rural Development Administration (RDA), "Standard Plan and Specification of Horticulture Facilities against Disaster", 2010, http://www.rda.go.kr (in Korea).

[3] Lee, T.-H., Lee, D.-G. and Ahn, S.-K., "The Repair and Strengthening of Vinyl-house Providing Against Heavy Snow", Proceedings of Architectural Institute of Korea, Seoul, South Korea, 2001, Vol. 21, No. 1, pp. 119-122.

[4] Lee, S.-G., Lee, J.-W. and Lee, H.-W., "Development of Reinforcement Strategy of One-span Vinyl House for Reduction of Damage by Heavy Snow", Journal of Bio-Environment Control, 2005, Vol. 14, No. 2, pp. 131-137.

[5] Kim, B.-K., Lee, S.-H. and Shin, K.-J., "Reinforcing Method of Plastic-house Frame for Heavy Snow using Pretension Tie", Proceeding of 7th International Symposium on Architectural Interchanges in Asia (ISAIA 2008), Beijing, China, 2008, pp. 876-879.

[6] Shin, D.-H., Lim, B.-H., Ju, G.-S. and Chae, S.-H., "Experimental Study on Strengthening Effect of Plastic Greenhouse using Tension-tie", Proceeding of 9th Pacific Structural Steel Conference (PSSC 2010), Beijing, China, 2010, pp. 1573-1580.

[7] ASCE/SEI 7-10, Minimum Design Loads for Buildings and Other Structures, American Society of Civil Engineering (ASCE), 2010.

[8] KBC 2009, Korean Building Code and Commentary, Architectural Institute of Korea (AIK), 2009.

[9] MIDAS IT, MIDAS/GEN 2016 User's Manual, MIDAS Information Technology Co., Ltd.,

[10] Kim, H.-J., Shin, K.-J., Kim, W.-J. and Huh, P.-S., "A Loading Apparatus for Frame of Arch Type (Patent No.1010434940000)", Korean Intellectual Property Office (KIPO), 2011.

[11] Kassimali, A., "Structural Analysis. 3rd ed", Nelson, 2005.

[12] Lee, S.-G., Shin, K.-J. and Lee, S.-H., "Plastic Analysis of Structure". Kimoondang, 2012 (in Korea). 